\title{
Medium modification with bone morphogenetic protein 2 addition for odontogenic differentiation
}

\section{Cigdem ATALAYIN(a) \\ Huseyin TEZEL(a) \\ Taner DAGCI (b) \\ Nefise Ulku \\ KARABAY YAVASOGLU(c) \\ Gulperi OKTEM(d)}

\footnotetext{
(a) Ege University, School of Dentistry, Department of Restorative Dentistry, Izmir, Turkey.

(b)Ege University, School of Medicine, Department of Physiology, Izmir, Turkey.

(c)Ege University, Faculty of Science, Department of Biology, Izmir, Turkey.

(d) Ege University, School of Medicine, Department of Histology and Embryology, Izmir, Turkey.
}

Declaration of Interests: The authors certify that they have no commercial or associative interest that represents a conflict of interest in connection with the manuscript.

\section{Corresponding Author: \\ Cigdem Atalayin \\ E-mail: dtcatalayin@gmail.com}

Submitted: Apr 06, 2015

Accepted for publication: Sep 18, 2015

Last revision: Nov 09, 2015

\begin{abstract}
The aim of this study was to evaluate whether medium modification improves the odontogenic differentiation of human dental pulp stem cells (DPSC) in vitro and in vivo. DPSC isolated from human impacted third molar teeth were analysed for clusters of differentiation with flow cytometry. Odontogenic differentiation was stimulated by medium modification with the addition of bone morphogenetic protein 2 (BMP2). The expression of dentin sialophosphoprotein, dentin matrix protein 1, enamelysin/matrix metalloproteinase 20 and the phosphate-regulating gene with homologies to endopeptidases on the $\mathrm{X}$ chromosome of the cells were analysed with RT-PCR at 7, 14 and 21 days. Then, DPSC were transplanted on the back of immunocompromised mice via a hydroxyapatite tricalcium phosphate scaffold, and the structure of the formed tissue was investigated. The cells were identified as mesenchymal stem cells with a 98.3\% CD73 and CD90 double-positive cell rate. The increase in mineralization capacity and expression of human enamel-dentin specific transcripts proportional to the culture period were determined after differentiation. Six weeks after transplantation, an osteo-dentin matrix was formed in the group in which odontogenic differentiation was stimulated, and the odontogenic characteristics of the matrix were confirmed by histological examination and RT-PCR analysis. Odontogenic differentiation of the isolated and characterized human DPSC was improved with medium modification by the addition of BMP2 in vitro and in vivo. The defined medium and applied technique have a potential use for forming reparative dentin in the future, but the effects of the method should be investigated in long-term studies.
\end{abstract}

Keywords: Bone Morphogenetic Protein 2; Dental Pulp; Regeneration.

\section{Introduction}

Terminal differentiation of pulp-derived stem cells into odontoblasts with external stimuli provides the formation of reparative dentin in required cases. ${ }^{1,2}$ Dental-tissue engineering targets generate new treatment alternatives with the regeneration potential of these cells. Dental pulp stem cells (DPSC) seem to be the most promising cell group for the regenerative approach. ${ }^{3,4,5}$ 
Growth and differentiation factors direct the function of the cells in the tissue according to the engineering concept. ${ }^{1,6}$ It is very important to understand and imitate the differentiation mechanism of the stem cells to ensure regeneration. Different growth factors are used to set the action of the various signals, and they provide cellular activation similar to the situation in the tissue. ${ }^{7,8}$ Bone morphogenetic proteins (BMP) located in bone and dentin induce osteo-dentin and then reparative dentin formation. ${ }^{6,910,11}$ Topical application of BMP or gene therapy is utilized to satisfy differentiation. ${ }^{10}$ Bone morphogenetic protein 2 (BMP2), which is expressed in the enamel knot, influences both epithelial and mesenchymal cells in tooth development and increases during the differentiation of odontoblasts. ${ }^{6,10} \mathrm{BMP} 2$ has been reported to ensure the differentiation of the pulp cells into the odontoblastic lineage and induce dentin formation in vitro and in vivo., $9,12,13,14$ Although the mentioned studies in animal cells yielded successful results, there is still a need to evaluate the response of human DPSC to BMP2 to create new odontogenic differentiation strategies for humans. In addition, studies on the topical application of BMP may allow the development of basic alternatives for differentiation.

The aim of this study was to evaluate whether a medium modified with BMP2 addition improves the odontogenic differentiation of human DPSC in vitro and in vivo. For this purpose, the effects of medium modification on odontogenic differentiation of the isolated and characterized human DPSC were determined with differentiation parameters based on the dental tissue engineering concept.

\section{Methodology}

\section{DPSC isolation and culture}

Human impacted third molar teeth collected from fifteen adults between 19 and 29 years old were used as the source of cells. The study protocol was approved by the Human Ethical Committee of Ege University (Research no. 09-9.1/6), and informed consent was obtained from the patients. After the extraction of a tooth (Figure 1A), gingival and periodontal tissues were removed and the tooth's surfaces were cleaned with povidone-iodine (Alcon Laboratories Inc., Fort
Worth, USA), alcohol and penicillin/streptomycin (Gibco Invitrogen, Grand Island, USA). Chamfers were created on the tooth surfaces with a diamond bur under physiological saline cooling, and the tooth was fractured (Figure 1B). The pulp tissue was removed and stored in a medium (alpha MEM, Gibco Invitrogen, Grand Island, USA) at $4^{\circ} \mathrm{C}$ until cell isolation, which was no later than 24 hours after removal of the tooth. The pulp tissue was cut into small pieces and then digested with $3 \mathrm{mg} / \mathrm{ml}$ collagenase type I (Sigma-Aldrich, St. Louis, USA) and $4 \mathrm{mg} / \mathrm{mL}$ dispase (Sigma-Aldrich, St. Louis, USA) for $45 \mathrm{~min}$ at $37^{\circ} \mathrm{C}$ (Figure 1C). Cell suspensions were obtained by passing the cells through a $70 \mathrm{~mm}$ strainer (Cell Strainer, BD Biosciences Discovery Labware, New Jersey, USA) (Figure 1D). The mesenchymal stem cell medium used for culturing the control (-) group contained an alpha modification of Eagle's medium (Gibco Invitrogen, Grand Island, USA) supplemented with 15\% fetal bovine serum (FBS) (Gibco Invitrogen, Grand Island, USA), $0.1 \mathrm{mM}$ L-ascorbic acid phosphate (Sigma-Aldrich, St. Louis, USA), 2 mM L-glutamine (Sigma-Aldrich, St. Louis, USA) and 100 units/mL penicillin/streptomycin (Gibco Invitrogen, Grand Island, USA). The cells seeded at $10 \times 10^{3}$ cells $/ \mathrm{cm}^{2}$ for culturing were incubated at $37^{\circ} \mathrm{C}$ in $5 \% \mathrm{CO}_{2}$, and the medium was changed every 48 hours. When the cells became confluent, they were subcultured. ${ }^{1,2,4}$

\section{Flow cytometry analysis}

Stem cells at 21-day culture periods were harvested and suspended in culture medium at a concentration of $1 \times 10^{6}$ cells $/ \mathrm{ml}$. Flow cytometry was performed using a FACS Calibur (BD Biosciences, New Jersey, USA), and the data were analysed with Cell Quest software (BD Biosciences, New Jersey, USA). CD34 (haematopoietic progenitor cell antigen; APC), CD45 (leucocyte common antigen/cell marker of haematopoietic origin; APC-H), CD73 (NTES'-nucleotidase; PE) and CD90 (thymus cell antigen/Thy-1/Thy-1.1; FITC) were used for immunophenotyping of DPSC.

\section{In vitro odontogenic differentiation of DPSC}

The defined medium was modified with the addition of 50 ng/mL BMP2 (Santa Cruz Biotechnology Inc., 

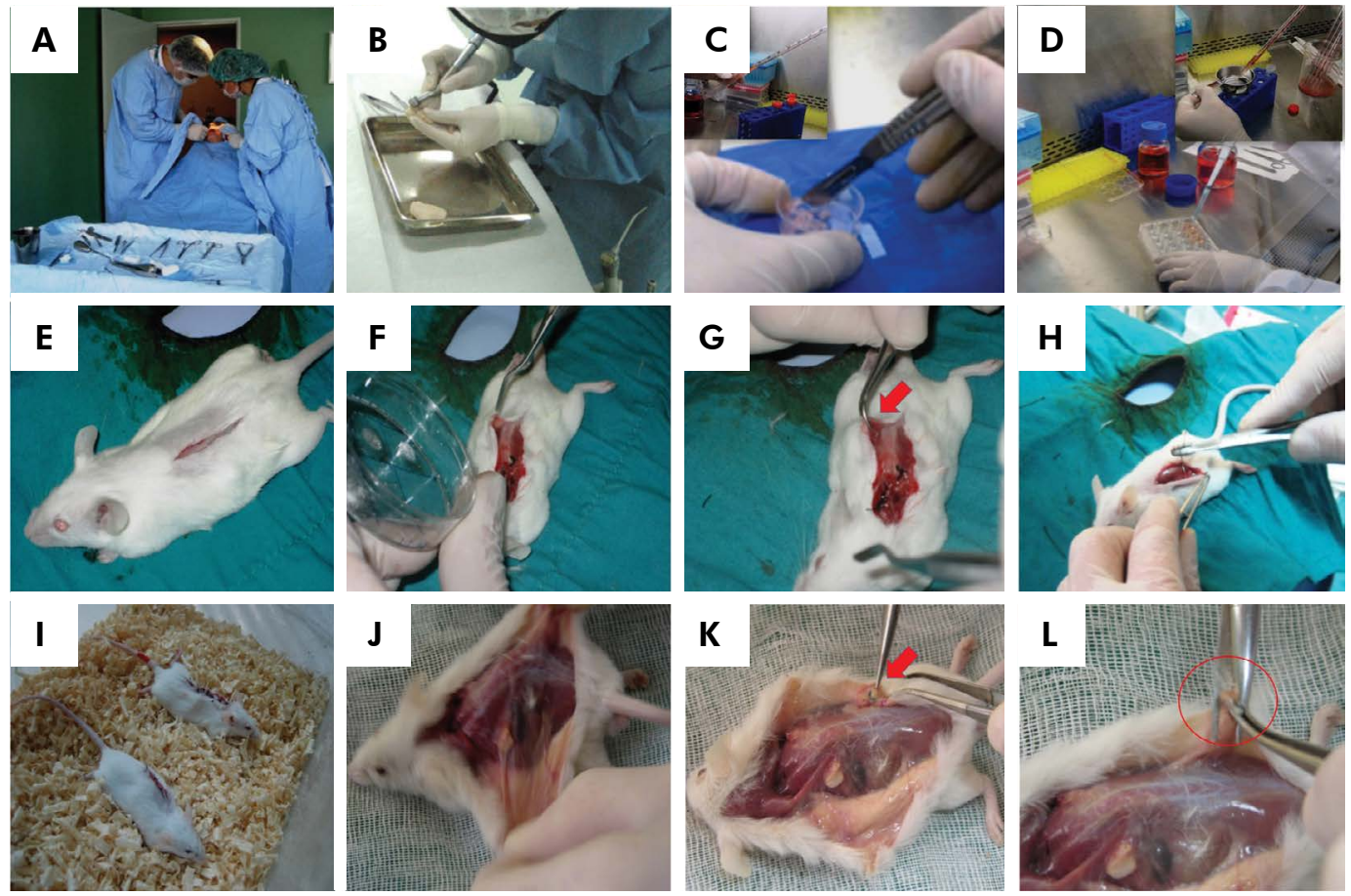

Figure 1. Stages of the method. (A) Tooth extraction. (B) Pulp tissue isolation. (C) and (D) Cell isolation and culture. (E-I) Transplantation. (J-L) Tissue formation after transplantation.

Texas, USA) to induce the odontogenic differentiation of DPSC in the experimental (+) group., ${ }^{4,9}$

\section{Microscopic examination}

The morphological changes were examined with an inverted microscope (Olympus, Tokyo, Japan). The mineralization was histologically detected by alizarin red (Fluka-Sigma Aldrich, Buchs, Switzerland).

\section{Reverse Transcription-Polymerase Chain Reaction (RT-PCR) analysis for dental pulp cells}

The expression of human enamel dentin-specific transcripts was evaluated using RT-PCR. The expression levels were determined for dentin sialo-phosphoprotein (Dspp), dentin matrix protein-1 (Dmp1), enamelysin/matrix metalloproteinase 20 (MMP20) and phosphate-regulating gene with homologies to endopeptidases on the $\mathrm{X}$ chromosome (Phex). For each time point at days 7, 14, and 21, total RNAs of dental pulp cells ( $1 \times 10^{6}$ cells in $200 \mu \mathrm{l}$ PBS) were isolated using the High Pure RNA Isolation
Kit (Roche, Cat No: 11828665 001) following the manufacturer's instructions. First-strand cDNAs were synthesized with a Transcriptor First Strand cDNA Synthesis Kit (Roche, Cat No 04379012 001) using total RNA. Specific primers were purchased (Table). A total of $0.3 \mathrm{ml}$ of each primer $(0.5 \mathrm{mM})$ was mixed with $10.5 \mathrm{~mL}$ of LightCycler FastStart DNA Master SYBR Green I kit (Roche, Cat no: 03003230 001) in a final volume of 18 millimeters. The standard cycling conditions were $95^{\circ} \mathrm{C}$ for 10 minutes, followed by 40 cycles of $95^{\circ} \mathrm{C}$ for $15 \mathrm{sec}, 62^{\circ} \mathrm{C}$ for $8 \mathrm{sec}$ and $72^{\circ} \mathrm{C}$ for 13 seconds. The comparative $\mathrm{Ct}$ method ( $2^{-\Delta \Delta \mathrm{Ct}}$ method) was used to determine and analyse the expression level of genes. ${ }^{15}$ The expression of cell-junctional genes was normalized using the glucose $\beta$-actin gene as a control housekeeping gene. The relative changes of the expression in the $(+)$ group compared to the $(-)$ group were determined as follows:

Ct: Threshold cycle, HKG: Housekeeping gene ( $\beta$-actin), GOI: Experimental gene, $\Delta \mathrm{Ct}$ (Control): $\mathrm{Ct}(\mathrm{GOI})-\mathrm{Ct}(\mathrm{HKG})$, $\Delta \mathrm{Ct}$ (Experimental): $\mathrm{Ct}(\mathrm{GOI})-\mathrm{Ct}(\mathrm{HKG}), \Delta \Delta \mathrm{Ct}: \Delta \mathrm{Ct}$ (Experimental) $-\Delta \mathrm{Ct}$ (Control), Fold change: $2^{-\Delta \Delta \mathrm{Ct}}$ 
Table. Primer sequences (forward and reverse) used in RT-PCR.

\begin{tabular}{ccc}
\hline \multicolumn{2}{c}{ Name } & Sequence \\
\hline 3-actin & Forward & 5' AGCCTCGCCTTTGCCGA \\
& Reverse & 5' CTGGTGCCTGGGGCG \\
Dspp & Forward & 5' AACATCACAGCAAATGGCATC \\
& Reverse & 5' CTTCCAGCTACTTGAGGTCCA \\
Dmpl & Forward & 5' AGACAGTGCCCAAGATACCACC \\
& Reverse & 5' ATTCCCTCATCGTCCAACTCG \\
MMP20 & Forward & 5' ACAAGCAGCCTCTAACTGGATC \\
& Reverse & 5' GATTTCGCATAAAGTTGCCCAT \\
Phex & Forward & 5' AACTTTGCTGCCTCAATGGGA \\
& Reverse & 5' GTCAATAAAGGCCCAGCGAAC \\
\hline
\end{tabular}

\section{Transplantation}

DPSC was cultured until the third passage in the (-) and (+) groups. Approximately $1 \times 10^{6}$ cells (for each group) were mixed with $40 \mathrm{mg}$ of hydroxyapatite tricalcium phosphate (HA/TCP) (Zimmer, Warsaw, USA) used as a scaffold and then transplanted into the pockets prepared on the subcutaneous dorsal surface of the immunocompromised mice (Figure 1E-I). Furthermore, the scaffold was transplanted without cells as a negative control group. All procedures were performed in accordance with the guidelines approved by the Animal Ethical Committee of Ege University (Research no. 2009-121). Six weeks after transplantation, the odontogenic structure of the formed tissue was analysed by RT-PCR.

Data were analysed using two-way ANOVA and Bonferroni tests. The differences were considered statistically significant at $\mathrm{p}<0.05$.
Moreover, for histological examination, $5 \mu \mathrm{m}$ wide paraffin-embedding sections were stained with haematoxylin and eosin (H\&E) (Sigma-Aldrich, St. Louis, USA) and alizarin red (Sigma-Aldrich, St. Louis, USA).

\section{Results}

Flow cytometry analysis: The cells were positive for mesenchymal cell markers (CD73 and CD90) but negative for haematopoietic markers (CD34 and CD45). Pair analysis was performed for mesenchymal CD, and the rate of CD73+ and CD90+ (double positive) was $98.3 \%$ after 21 days of incubation (Figure 2).

Microscopic examination: The isolated cells adhered to the plastic culture plate and had a fibroblast-like appearance and then began to proliferate and gradually grow to form small colonies. The primary cells reached confluency 21 days after planting and were ready for passage, but the cell density and colony formation were higher in the $(+)$ group (Figure 3). The foci of mineralization indicating odontogenic differentiation were observed in the $(+)$ group with alizarin red staining from the third week of the culture (Figure 3).

RT-PCR results: The expressions of Dspp, Dmp1, enamelysin/MMP20 and Phex were higher in the $(+)$ group than in the (-) group, and this increase proportionally reached the highest level on the twenty-first day of the culture period (Figure 4).

Six weeks after transplantation: Cellular activation did not occur in the negative control group, and only the granular structure of the scaffold was evident (Figure 5A). An increase
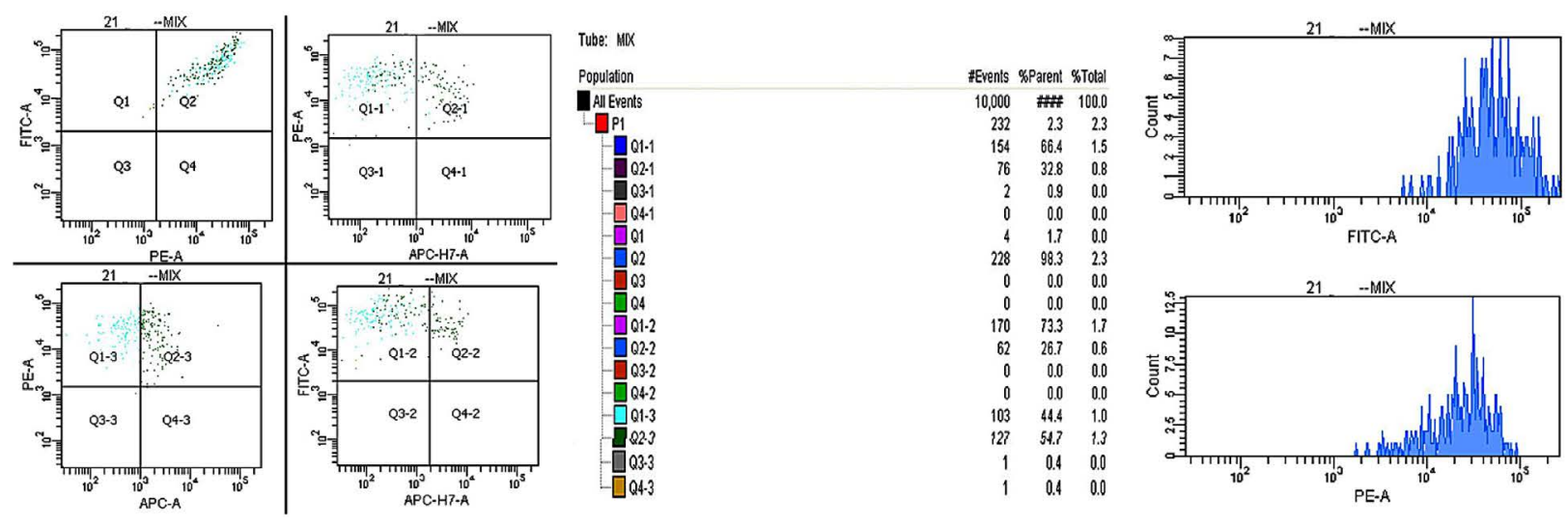

Figure 2. The double-positive areas and expression rates of DPSC after 21 days. Q2: CD73 (PE) + CD90 (FITC). 

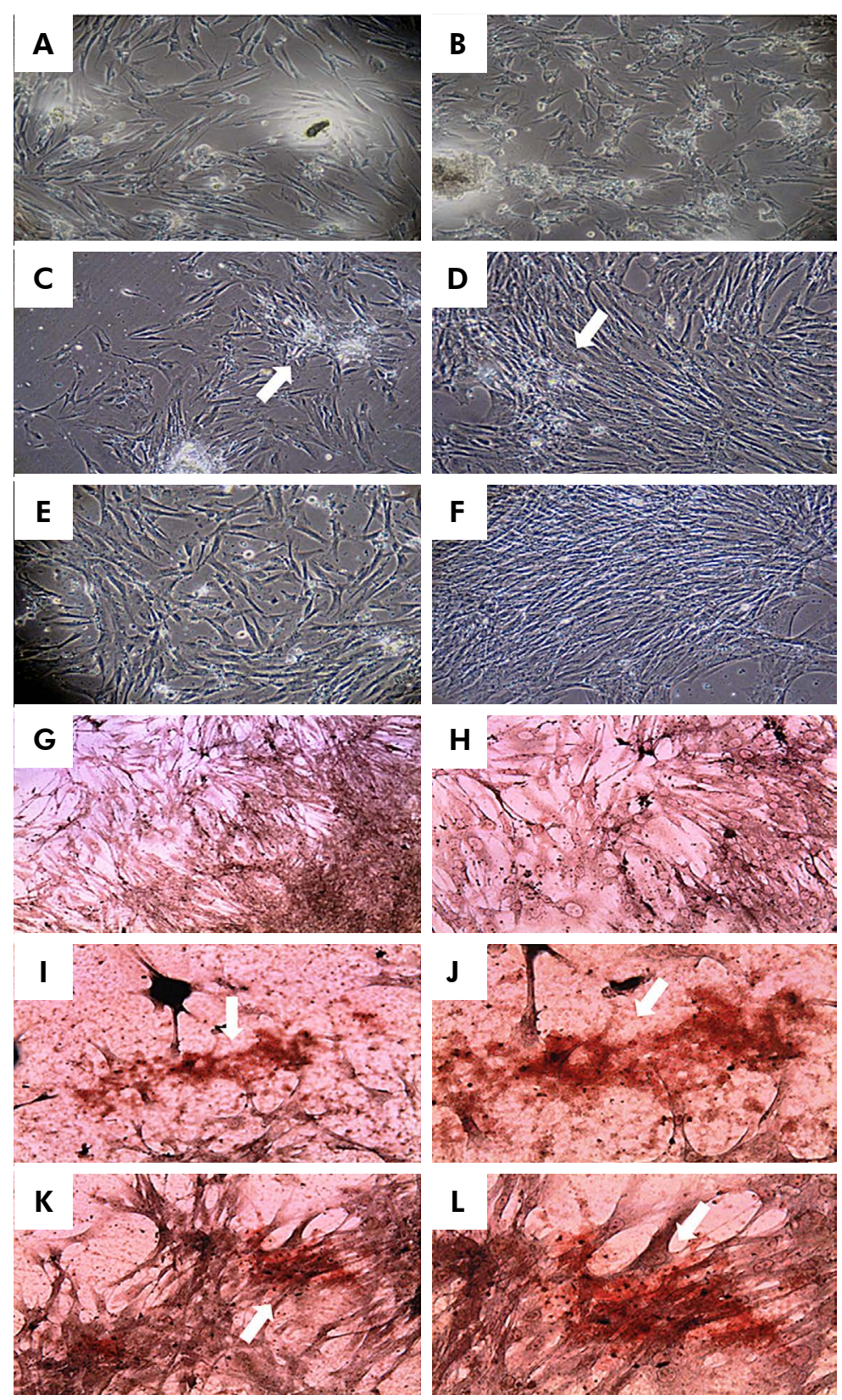

Figure 3. The cell proliferation and colony formation (arrows) during the culture period $[(A, C$ and $E):(-)$ group. $(B, D$ and $F):(+)$ group. ( $A$ and $B): 7^{\text {th }}$ day; $(C$ and $D): 14^{\text {th }}$ day; $E$ and F: $21^{\text {th }}$ day, inverted microscopy $\left.\times 100\right]$. No sign of mineralization in the (-) group $(\mathrm{PI}, \mathrm{G}: \times 20 ; \mathrm{H}: \times 40)$. The foci of mineralization (arrows) indicating odontogenic differentiation from the third week of culture after alizarin red staining in the $(+)$ group $(\mathrm{Pl}, \mathrm{I}$ and $\mathrm{K}: \times 20 ; \mathrm{J}$ and $\mathrm{L}: \mathrm{x} 40)$.

in connective tissue cells and the formation of granulation-like tissue were found in the (-) group (Figure 5B). An increase in odontoblast-like cell density, scaffold-tissue integration, vascularization and osteo-dentin matrix formation occurred in the $(+)$ group (Figure 5C). No mineralization foci were detected in the negative control group, and only dye accumulation was observed at the periphery of the sections (Figure 5D). Mild mineralization was detected in the (-) group (Figure 5E), otherwise increased calcification and mineralized areas were found in the $\left(^{+}\right)$group (Figure 5F).

Mineralized tissue formation and scaffold-tissue integration were noticed macroscopically in the $(+)$ 
group (Figure 1J-L). Odontogenic characteristics of the matrix structure were also confirmed with the gene expression (Figure 6). The fold increase in Dspp expression level was determined in the $(+)$ group compared to the $(-)$ group $(\mathrm{p}<0.05)$.
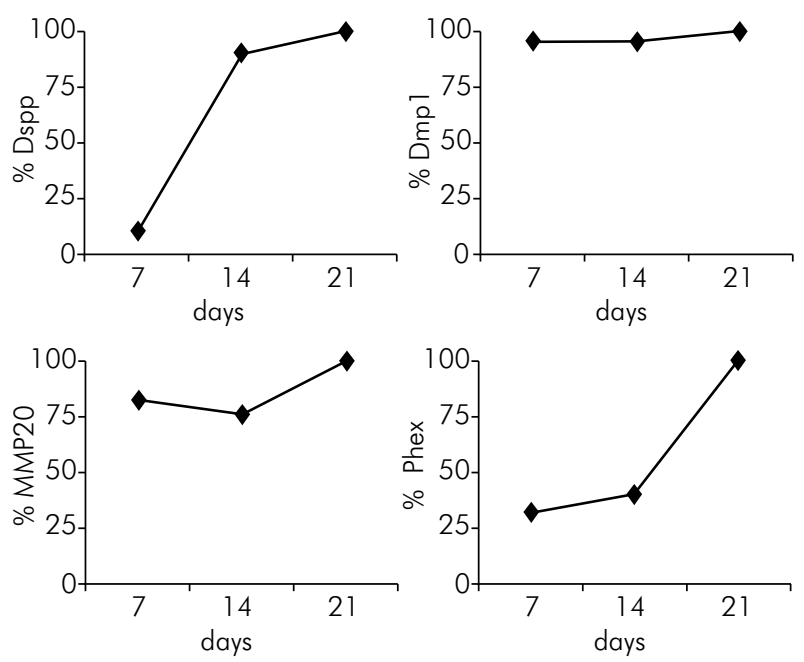

Figure 4. The fold increase in the expression levels of the $(+)$ group compared to the (-) group for Dspp, Dmp 1, MMP20 and Phex at the $7^{\text {th }}, 14^{\text {th }}$ and $21^{\text {th }}$ culture days (The relative percentages of expression were shown in relation to the highest value as $100 \%$ after normalization against $\beta$-actin).

\section{Discussion}

The triad of stem cells, morphogens and scaffolds compose the key elements of regeneration., ${ }^{1,6,11}$ Stem cells derived from the same region are beneficial for use in the regeneration of a specific tissue. For example, dental tissue-derived stem cells may be a cell source for many tissues, but the odontogenic differentiation potential for such stem cells is higher., ${ }^{3,16,17}$ Therefore, dental pulp tissue obtained from human impacted third molar teeth were used as a stem cell source in this study on odontogenic differentiation. Identifying the stem cells is an important step and necessary for characterization. ${ }^{1,4}$ The specific mesenchymal stem cell isolation method and medium ${ }^{1,2,4}$ were used in this study. Then, flow cytometry analysis was performed for the characterization of the isolated cells. Different surface markers were analysed to define the dental tissue-derived stem cells in a variety of studies, but a standard combination of markers is

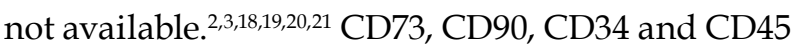
were analysed according to the International Society of Cellular Therapy (ISCT) criteria, ${ }^{18}$ and our results (Figure 2) were consistent with previous studies. 2,3,20,21 CD73 and CD90 positive cells have been reported to compose more than $95 \%$ of the population for the identification of mesenchymal stem cells. ${ }^{18}$ The

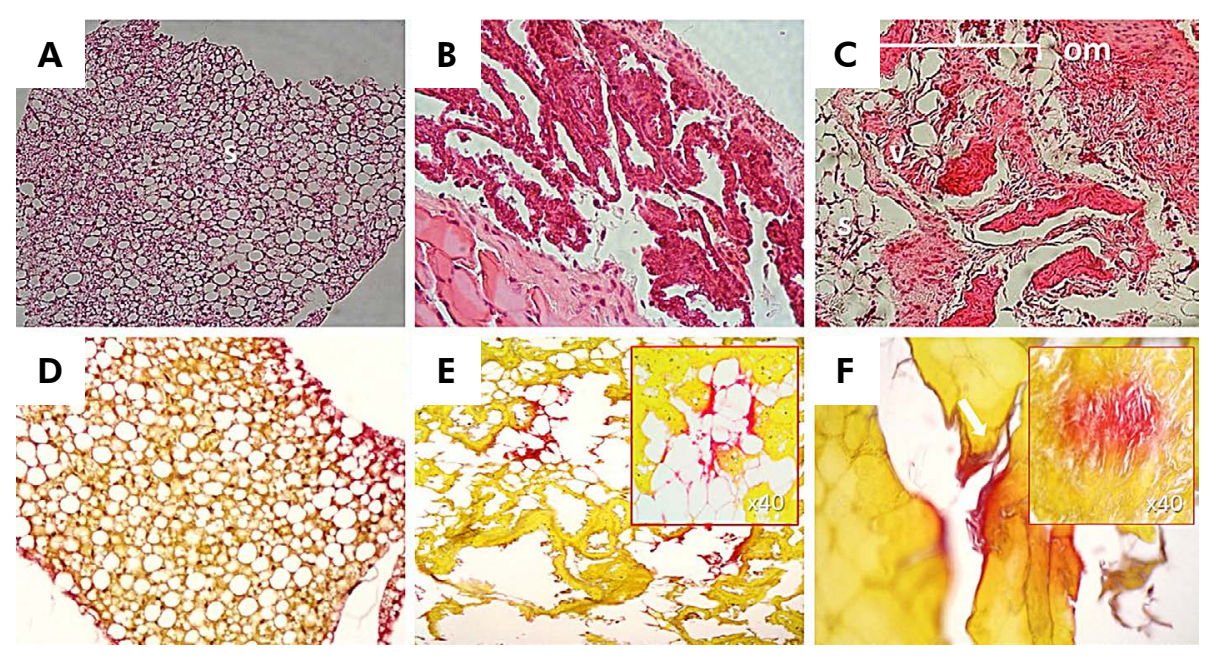

Figure 5. The $H \& E(A, B$ and $C)$ and alizarin red $(D, E$ and $F)$ staining images of the developed tissue 6 weeks after transplantation (x20). (A): The granular structure of the scaffold (s) in the negative control group. (B): The increase in connective tissue cells and the formation of granulation-like tissue in the (-) group. (C): The increase in odontoblast-like cell density, tissue organization, vascularization (v) and osteo-dentin matrix (om) formation in the (+) group. (D): No mineralization foci in the negative control. (E): Mild mineralization in the (-) group. (F): Increased calcification and mineralized areas (arrow) in the (+) group. 


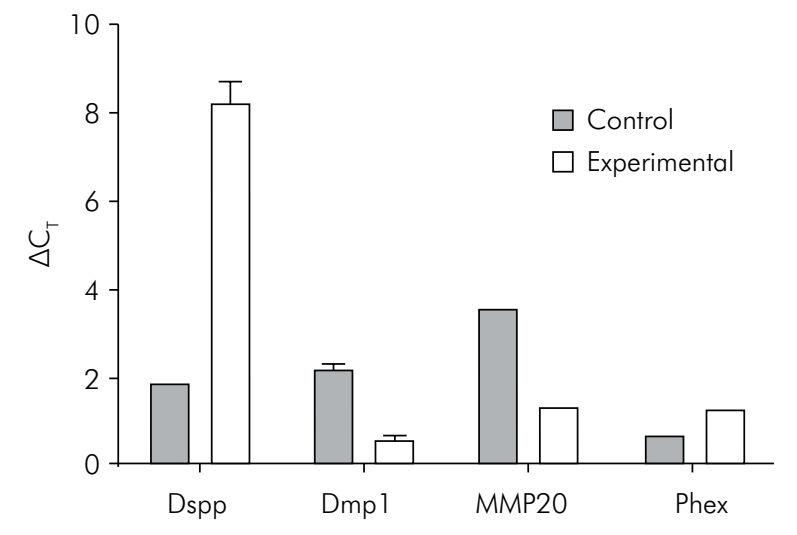

Figure 6. The expression levels of Dspp, Dmp 1, MMP20 and Phex in the $(-)$ and $(+)$ groups six weeks after transplantation.

mentioned expression level detected as being 98.3\% was a result of selective cell proliferation in this study, and thus the isolated cells were confirmed to be mesenchymal stem cells with a better expression rate set than in the criteria. Additionally, the cell characterization was performed without any differentiation to determine the pure content of stem cells.

Morphogens are used to generate biosignals and provide an environment similar to the tissue for stem cells in vitro, ${ }^{7}$ but the use of a single factor is recommended to prevent cellular exchange and provide a controlled investigation..$^{22}$ Thus, only BMP2 was defined as an inductive factor for odontogenic differentiation, and then reparative dentin formation ${ }^{6,9,10,23}$ was used in the study. As the complex methods such as morphogen production and gene therapy have many challenges, ${ }^{10}$ the differentiation was induced by the topical application of BMP2. The reported ${ }^{9,11}$ most effective dose of BMP2 (50 ng/mL BMP2) was added to the medium. Because the combination of BMP and dexamethasone has greater induction capacity, ${ }^{11}$ the medium supplemented with dexamethasone sodium phosphate was preferred. The synergistic effect of the other proteins should also be investigated in further studies to generate the optimal differentiation medium.

BMP2 has not been reported to make a difference for the amount of stem cells and the proliferation rate. ${ }^{9}$ Although a CFU-assay was not performed in this study, an increase in the cell density and colony formation was observed (Figure 3 ) in the $(+$ ) group as a novel finding. Calcified deposit formation and an increase in mineralization capacity have been reported as the most important indicators of odontogenic differentiation. ${ }^{1,24,9,23}$ While no mineralization indicator was found in the (-) group, the mineralization foci mentioned in other studies ${ }^{1,2,4}$ occurred and increased after the third week in the culture of the $(+)$ group (Figure 3). However, it seems to be pretentious to suggest that the mineralization was only a result of odontogenic differentiation. Mineralization may occur in many physiological or pathological conditions, and the existing biomarkers can provide insight for the process. For instance, enamel and dentin specific transcript expression have been reported as necessary to confirm odontogenic differentiation. ${ }^{24}$ Therefore, gene expression analysis was also performed for human enamel-dentin specific transcripts in this study. The increased expression responsible for the formation of predentin matrix (Dspp) ${ }^{25}$ collagen (Dmp1), ${ }^{26}$ enamel matrix, (MMP20) ${ }^{27}$ and phosphate haemostasis (Phex) ${ }^{28}$ consistent with the culture period in the $(+)$ group compared to the (-) group (Figure 4) were the evidence of odontogenic differentiation. In addition, the increased expression of all transcripts on the $21^{\text {th }}$ day, known as the initial period of the dentin formation, supports our findings.

Although in vitro culture systems have created a basic model, in vivo implantation systems are necessary to identify the structural properties of the tissue formed after differentiation..$^{1,2}$ DPSC induced for odontogenic differentiation were transplanted to mice in the in vivo part of our study. As recommended, ${ }^{29}$ the cells from the third passage were used to avoid the risks of cell ageing and cytogenetic disorders. HA-TCP, which qualified as odonto-conductive and has had routine use in dentistry, ${ }^{2,3}$ was preferred as the scaffold. Consequently, a bioactive method comprising DPSC, modified medium with BMP2 addition and HA-TCP was enhanced and applied.

Stem cells have been reported as essential for odontogenic regeneration, ${ }^{1}$ and this condition was confirmed by no tissue organization occurring in the negative control group (Figure 5A). Tissue organization, matrix formation and calcification have been noted to be the key elements of odontogenic 
regeneration. ${ }^{2,3,30}$ Although only granulation tissue formation was detected in the control (-) group (Figure 5B), scaffold-tissue integration, and increased cellular activation, vascularization, and mineralization contributed to osteo-dentin like matrix formation in the $(+)$ group (Figure 5C and 5F). Therefore, the required elements were present.

The odontogenic characteristics of the matrix structure formed in the study was confirmed by the presence of the related gene expression (Figure 6), and in vivo findings consistent with the studies ${ }^{2,3,30}$ were also obtained for DPSC after transplantation. The transplantation period of the study was defined as 6 weeks to follow the changes in the early stages, ${ }^{2,3,30}$ but the expression in different time periods should be examined. The increased Dspp expression level (Figure 6) in the (+) group could be accepted as the indicator of odontogenic matrix formation as a result of odontoblastic differentiation and activity. ${ }^{26}$ The expression levels of the other transcripts change and increase in the periods following the gradual tooth

\section{References}

1. Mauth C, Huwig A, Graf-Hausner U, Roulet J-F. Restorative applications for dental pulp theraphy. In: Ashammakhi N, Reis R, Chiellini E, editors. Vol. 3, Topics in tissue engineering [Internet]. Tampere: Expertissues; 2007 [cited 201511 06]. p. 1-32. Available from: http://www.oulu.fi/spareparts/ ebook_topics_in_t_e_vol3/

2. Gronthos S, Mankani M, Brahim J, Robey PG, Shi S. Postnatal human dental pulp stem cells (DPSCs) in vitro and in vivo. Proc Natl Acad Sci USA. 2000;97(25):13625-30. doi:10.1073/pnas.240309797

3. Gronthos S, Brahim J, Li W, Fisher LW, Cherman N, Boyde A, et al. Stem cell properties of human dental pulp stem cells. J Dent Res. 2002;81(8):531-5. doi:10.1177/154405910208100806

4. Sonoyama W, Yamaza T, Gronthos S, Shi S. Multipotent Stem Cells In Dental Pulp. In: Freshney IA, Stacey GN, Auerbach JM, editors. Culture of Human Stem Cells. New Jersey: Wiley-Liss; 2007. p. 187-206.

5. La Noce M, Paino F, Spina A, Naddeo P, Montella R, Desiderio $\mathrm{V}$, et al. Dental pulp stem cells: state of the art and suggestions for a true translation of research into therapy. J Dent. 2014;42(7):761-8. doi:10.1016/j.jdent.2014.02.018

6. Nakashima M, Reddi AH. The application of bone morphogenetic protein to dental tissue engineering. Nat Biotechnol. 2003;21(9):1025-32. doi:10.1038/nbt864 development stage. Moreover, further investigations into different conditions (different growth factors, different culture environments, etc.) are required.

\section{Conclusion}

Odontogenic differentiation of the isolated and characterized human DPSC was improved with the in vitro medium modification by the addition of BMP2. The applied induction also ensures in vivo odontogenic matrix formation. Therefore, the defined medium and applied technique have a potential use in forming reparative dentin in the future, but the effects of the method should be investigated in the long-term with different scaffold materials.

\section{Acknowledgements}

This study was supported by Ege University's Scientific Research Foundation (2009-Dis-036). We also acknowledge The Scientific and Technological Research Council of Turkey (TUBITAK) for its PhD scholarship support.

7. Baum BJ, Mooney DJ. The impact of tissue engineering on dentistry. J Am Dent Assoc. 2000;131(3):309-18. doi:10.14219/jada.archive.2000.0174

8. Taipale J, Keski-Oja J. Grow factors in the extracellular matrix. FASEB J. 1997;11(1):51-9.

9. Iohara K, Nakashima M, Ito M, Ishikawa M, Nakashima A, Akamine A. Dentin regeneration by dental pulp stem cell therapy with recombinant human bone morphogenetic protein 2. J Dent Res. 2004;83(8):590-5. doi:10.1177/154405910408300802

10. Nakashima M. Bone morphogenetic proteins in dentin regeneration for potential use in endodontic therapy. Cytokine Growth Factors Rev. 2005;16(3):369-76. doi:10.1016/j.cytogfr.2005.02.011

11. Wang J, Liu X, Jin X, Ma H, Hu J, Ni L, et al. The odontogenic differentiation of human dental pulp stem cells on nanofibrous poly (L-lactic acid) scaffolds in vitro and in vivo. Acta Biomater. 2010;6(10):3856-63. doi:10.1016/j.actbio.2010.04.009

12. Nakashima M. Induction of dentin formation on canine amputated pulp by recombinant human bone morphogenetic protein (BMP)-2 and -4. J Dent Res. 1994;73(9):1515-22. doi:10.1177/00220345940730090601

13. Nakashima M. Induction of dentine in amputated pulp of the dogs by recombinant human bone morphogenetic proteins-2 and -4 with collagen matrix. Arch Oral Biol. 1994;39(12):1085-89. doi:10.1016/0003-9969(94)90062-0 
14. Yang X, Walboomers XF, van den Beucken JJ, Bian Z, Fan M, Jansen JA. Hard tissue formation of STRO-1-selected rat dental pulp stem cells in vivo. Tissue Eng Part A. 2009;15(2):367-75. doi:10.1089/ten.tea.2008.0133

15. Livak KJ, Schmittgen TD. Analysis of relative gene expression data using real-time quantitative PCR and the $2^{-\Delta \Delta \mathrm{Ct}}$ method. Methods. 2001;25(4):402-8. doi:10.1006/meth.2001.1262

16. Huang GT, Gronthos S, Shi S. Mesenchymal stem cells derived from dental tissues vs. those from other sources: their biology and role in regenerative medicine. J Dent Res. 2009;88(9):792-806. doi:10.1177/0022034509340867

17. Mayo V, Sawatari Y, Huang CY, Garcia-Godoy F. Neural crest-derived dental stem cells- where we are and where are going. J Dent. 2014;42(9):1043-51. doi:10.1016/j.jdent.2014.04.007

18. Dominici M, Le Blanc K, Mueller I, Slaper-Cortenbach I, Marini F, Krause D, et al. Minimal criteria for defining multipotent mesenchymal stromal cells. The International Society for Cellular Therapy position statement. Cytotherapy. 2006;8(4):315-7. doi:10.1080/14653240600855905

19. Horwitz EM, Le Blanc K, Dominici M, Mueller I, Slapercortenbach I, Marini FC, et al. Clarification of the nomenclature for MSC: The International Society for Cellular Therapy position statement. Cytotherapy. 2005;7(5):393-5. doi:10.1080/14653240500319234

20. Karaöz E, Doğan BN, Aksoy A, Gacar G, Akyüz S, Ayhan $S$, et al. Isolation and in vitro characterisation of dental pulp stem cells from natal teeth. Histochem Cell Biol. 2010;133(1):95-112. doi:10.1007/s00418-009-0646-5

21. Yalvaç ME, Rmaazanoğlu M, Gumru OZ, Şahin F, Palotas A, Rizvanov AA. Comprasion and optimisation of transfection of human dental folicle cells, a novel source of stem cells, with different chemical methods and electro-poration. Neurochem Res. 2009;34(7):1272-7. doi:10.1007/s11064-008-9905-4

22. Wynn RF, Hart CA, Corradi-Perini C, O'Neill L, Evans CA, Wraith JE, et al. A small proportion of mesenchymal stem cells strongly expresses functionally active CXCR4 receptor capable of promoting migration to bone marrow. Blood. 2004;104(9):2643-5. doi:10.1182/blood-2004-02-0526

23. Iohara K, Zheng L, Ito M, Tomokiyo A, Matsushita K, Nakashima M. Side population cells isolated from porcine dental pulp tissue with self-renewal and multipotency for dentinogenesis, chondrogenesis, adipogenesis, and neurogenesis. Stem Cells. 2006;24(11):2493-2503. doi:10.1634/stemcells.2006-0161

24. Yun YR, Jeon E, Lee S, Kang W, Kim SS, Kim HW, et al. Expression, purification and characterization of a dentin phosphoprotein produced by E.coli, and its odontoblastic differentiation effects on human dental pulp cell. Protein J. 2012;31(6):504-10. doi:10.1007/s10930-012-9430-9

25. MacDougall M, Simmons D, Luan X, Nydegger J, Feng J, $\mathrm{Gu}$ TT. Dentin phosphoprotein and dentin sialoprotein are cleavage products expressed from a single transcript coded by a gene on human chromosome 4 . Dentin phosphoprotein DNA sequence determination. J Biol Chem. 1997;272(2):835-42. doi:10.1074/jbc.272.2.835

26. Aplin HM, Hirst KL, Crosby AH, Dixon MJ. Mapping of the human dentin matrix acidic phosphoprotein gene (DMP1) to the dentinogenesis imperfecta type II critical region at chromosome 4q21. Genomics. 1995;30(2):347-9. doi:10.1006/geno.1995.9867

27. Hu JC-C, Chun Y-HP, Al Hazzazzi TA, Simmer JP. Enamel formation and amelogenesis imperfecta. Cells Tissues Organs. 2007;186(1):78-85. doi:10.1159/000102683

28. Ruchon AF, Marcinkiewicz M, Siegfried G, Tenenhouse HS, DesGroseillers L, Crine P, et al. Pex mRNA is localized in developing mouse osteoblasts and odontoblasts. J Histochem Cytochem. 1998;46(4):459-68. doi:10.1177/002215549804600405

29. Pittenger MF, Mackay AM, Beck SC, Jaiswal RK, Douglas $\mathrm{R}$, Mosca JD, et al. Multilineage potential of adult human mesenchymal stem cells. Science. 1999;284(5411):143-7. doi:10.1126/science.284.5411.143

30. Zhang W, Frank Walboomers $X$, van Kuppevelt TH, Daamen WF, Bian Z, Jansen JA. The performance of human dental pulp stem cells on different three-dimensional scaffold materials. Biomaterials. 2006;27(33):5658-68. doi:10.1016/j.biomaterials.2006.07.013 